This item was submitted to Loughborough's Research Repository by the author.

Items in Figshare are protected by copyright, with all rights reserved, unless otherwise indicated.

\title{
Freeform construction: mega-scale rapid manufacturing for construction
}

PLEASE CITE THE PUBLISHED VERSION

http://dx.doi.org/10.1016/j.autcon.2006.05.002

\section{PUBLISHER}

(c) Elsevier

VERSION

AM (Accepted Manuscript)

LICENCE

CC BY-NC-ND 4.0

\section{REPOSITORY RECORD}

Buswell, Richard A., Rupert C. Soar, Alistair G.F. Gibb, and Tony Thorpe. 2019. "Freeform Construction: Mega-scale Rapid Manufacturing for Construction”. figshare. https://hdl.handle.net/2134/9925. 
This item was submitted to Loughborough's Institutional Repository (https://dspace.lboro.ac.uk/) by the author and is made available under the following Creative Commons Licence conditions.

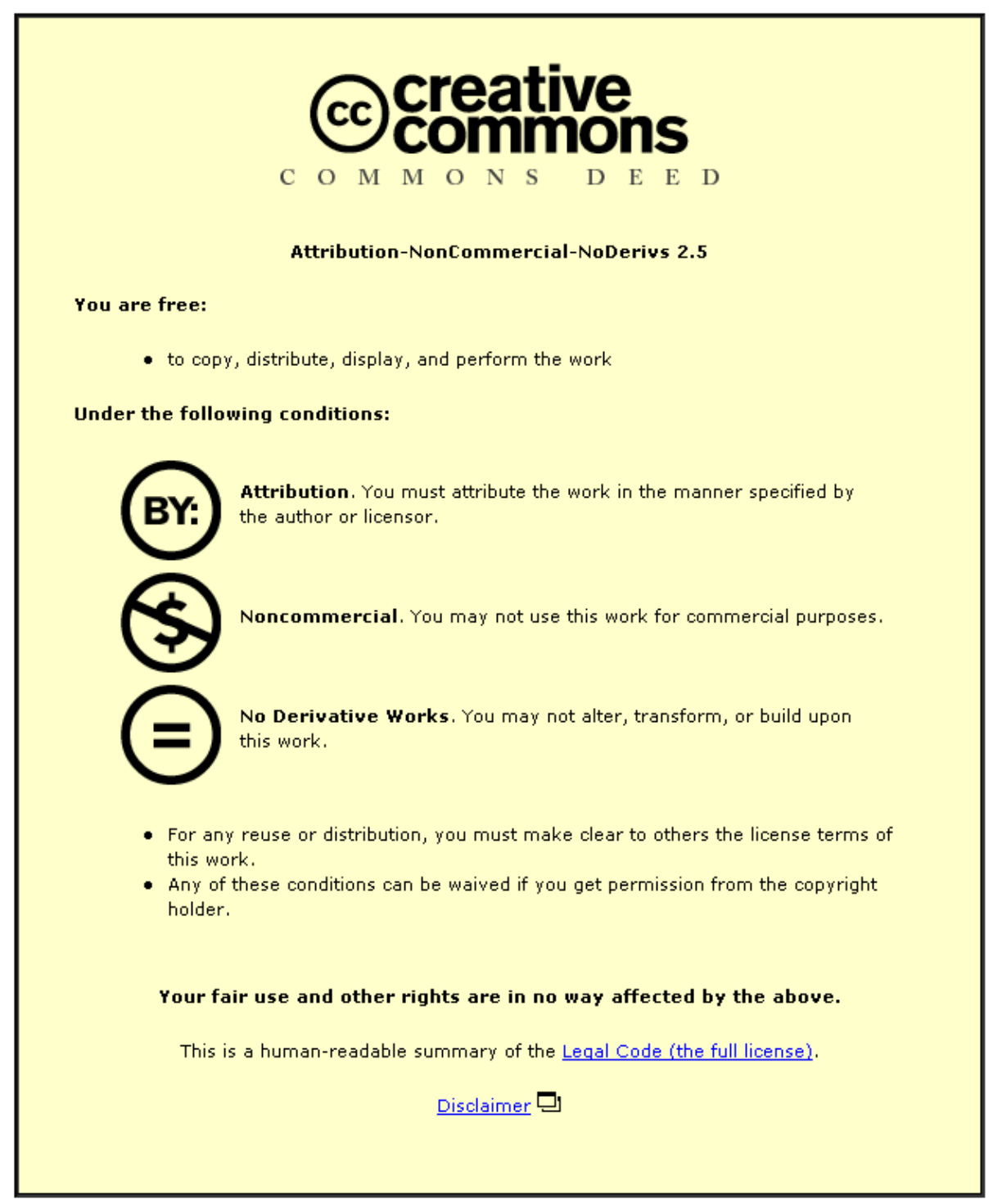

For the full text of this licence, please go to: http://creativecommons.org/licenses/by-nc-nd/2.5/ 


\title{
Freeform Construction: Mega-Scale Rapid Manufacturing for Construction
}

\author{
R. A. Buswell ${ }^{1}$ R. C. Soar ${ }^{1}$, A. G. F. Gibb ${ }^{2}$ and A. Thorpe ${ }^{2}$ \\ 1: Wolfson School of Mechanical and Manufacturing Engineering, \\ Loughborough University \\ 2: Civil and Building Engineering, Loughborough University
}

\begin{abstract}
Abstact
The utilisation of automation technology and processes control found in the automotive and aerospace industries is not paralleled in modern day construction. The industry also struggles to improve health and safety issues and still uses traditional methods of procurement. These problems are compounded by diminishing skills in the labour force. Methods of production must change if these issues are to be resolved. Rapid Manufacturing is a family of digitally controlled additive processes that have the potential to impact on construction processes. This paper outlines some of the major issues facing construction technology and give examples of the use of large scale digital fabrication in the industry. The term 'Freeform Construction' is defined. Potential applications derived from an industrial workshop are presented and results from a series of preliminary studies indicate the viability of mega-scale Rapid Manufacturing for construction.
\end{abstract}

Key Words: Construction Automation; Rapid Manufacturing; Freeform Construction; Rapid Prototyping; Solid Freeform Fabrication.

\section{Introduction}

Rapid Prototyping processes such as Stereolithography have been utilised by the aerospace, automotive and consumer industries over the last two decades [1]. The utilisation of these methods within the construction industry is set to increase; architectural modelling is a growing application [2-5]. Processes such as 3D printing is becoming popular in mainstream architectural modelling applications; leading architects Foster and Partners (London, UK), for example, have a dedicated machine used by their Specialist Modelling Group.

Rapid Prototyping processes can be applied, conceptually at least, at any scale from desktop model to full scale building construction. Modelling is a typical application today, while full scale construction is more speculative. This paper reviews the status of the construction industry in terms of it's problems and the use of Digital Fabrication. Rapid Prototyping and Rapid Manufacturing are described and construction applications are discussed. The paper responds to recent calls for the development of new processes [6] by defining the concept of Freeform Construction and discussing potential viability.

\footnotetext{
${ }^{1}$ Corresponding author. Email address: r.a.buswell@lboro.ac.uk
} 


\section{The Problems Facing Construction}

In terms of technological development and fulfilment of customer expectation, it can be argued that construction is decades behind other industries such as aerospace, automotive and ship building. The fundamental principles of construction have not changed for hundreds of years; the Romans invented concrete about 100BC and 2200 years later we are still using it as a primary build material and (more or less) controlling placement with the human hand. Construction technologies are limiting imagination and hence stifling innovation; new methods of production and assembly often result in moving the 'hand trades' away from the construction site rather than developing radical new processes. Often the procurement and legal requirements that enable construction act as a disincentive to try different approaches.

Competition for projects concentrate on first-cost; the cheapest bid wins and there is little time, money or energy to invest in innovation. The industry is also conservative and any innovations only generate incremental changes. Where changes and improvements are made, the transient nature of the work and workforce often means that these improvements are not adopted on new projects as they might in a more 'static' manufacturing environment. There is a growing skills shortage, which will be compounded in the future by the aging population apparent in the UK and like countries. Safety is still an important issue; construction remains a hazardous environment. In addition, the industry is likely to face increasing pressures from developing environmental issues [7].

The UK government has been addressing these issues through a succession of initiatives, prompted by the Latham and Egan Reports [8,9] and ultimately by 'Constructing Excellence.' The drive is towards leaner, better Modern Methods of Construction (MMC) [10]. Some of these issues have been addressed by standardisation and pre-assembly [11]. There is, however a need for a more radically different solutions. As human endeavour pushes further forward, construction will need to be able to respond to unique challenges in aggressive environments such as for polar, desert, developments, chemical contamination and off-world applications. We will need to respond to environmental issues with new materials and new solutions for buildings at the end of life.

Process automation offers a large departure from conventional methods of construction. This has largely been investigated in terms of robotics [12-16]. Creating large scale 'on-site factory' environments have been demonstrated by the construction of the Shimizu Corporation building [17] and others.

\section{Rapid Manufacturing}

Rapid Manufacturing, Rapid Prototyping, Solid Freeform Fabrication, Additive Manufacturing Technologies, all refer to the same family of processes. In broad terms, these processes all produce components by adding, or building up, material to form an object. The process is therefore additive, hence the name. These processes contrast traditional methods that are either: Subtractive, starting with a block and machining away the material that is not required; or formative, shaping or casting material in a mould.

These methods were developed originally to quickly produce prototype models. The name Rapid Prototyping described the time saving associated with the negation of the human model, or tool maker required to create the object for evaluation as part of the design process. Rapid Manufacturing is the term applied when Rapid Prototyping 
machines are used to produce end use parts directly. In the US, Solid Freeform Fabrication is the preferred term for Rapid Prototyping or Rapid Manufacturing. The term Rapid Manufacturing will be used throughout this paper and some common process are summarised in Table 1.

Table 1

Summary of common Rapid Manufacturing techniques[1].

All of these processes work on similar principles, Figure 1 depicts the 3D printing process. A 3D solid model of the desired component is created in $\mathrm{CAD}^{2}$ software (1). The model is then typically translated into ' $\mathrm{STL}^{3}$ ', a standard data format that can be used by most Rapid Manufacturing machines. This describes the surface of the object and can then be 'sliced' into layers so that the part can be constructed sequentially (2). Each layer is then sent to the machine (3) and the information used to control the location of a printer head. The printer head deposits a binder on a fine layer of powdered material where the layer is to be made solid ${ }^{4}(4)$. The machine reconstructs a $3 \mathrm{D}$ object by sequentially bonding these ' $2 \mathrm{D}$ ' layers of material.

Fig. 1. A representation of the 3D printing process.

Rapid Manufacturing has come through an evolution. Early versions could not produce robust components that could be classed as 'end-use' parts and this was largely down to the quality of the materials. Materials development plays a key role in realising true functionality in parts produced using Rapid Manufacturing technologies. Highly engineered components, such as camshafts, gearboxes, etc. can not yet be manufactured using SLA or SLS type processes. Within the additive process family, however, advances in technologies such as Rolls Royce's (Derby, UK) Shaped Metal Deposition process and Optomec's (Albuquerque, US) Laser Engineered Net Shape process are capable of providing fully dense metal parts with fewer defects than the forging or casting alternatives $[18,19]$.

It should also be noted that, contrary to the name, Rapid Manufacturing is not concerned with speeding up manufacturing process; it simply eliminates the need for tooling and so shortens time to manufacture. A useful by-product of this approach is almost unlimited geometrical freedom and that moving parts can be constructed in a single build, negating the need for assembly. The perceived benefits of these processes are, therefore, adding value to products. A principle driver for Rapid Manufacturing is product customisation and/or personalisation at no extra cost. There is significant interest in these technologies for the delivery of medical services such as better fitting burn masks that improve recovery and the investigation of hydrogel scaffolds for tissue repair applications [1, 20]. Rapid Manufacturing has found a niche market in dental care. In the US, Invisalign Technologies [21] offer a clear plastic product that straightens teeth as alternative to metal braces. The technique uses a CAD model of the teeth to be straightened and a number of staged corrections are generated to bring the teeth into alignment. The product uses Stereolithography to produce the forms for the plastic aligners. Every aligner is unique and Rapid Manufacturing processes are the only way in which this level of customisation is viable. The product has been embraced by $85 \%$ of Orthodontists in the US and thousands of dentists [1].

\footnotetext{
${ }^{2}$ Computer Aided Design, or Drafting.

${ }^{3}$ Stereolithography Language.

${ }^{4}$ In actual fact, the $\mathrm{Z}$ Corporation 3D printing process (depicted in Figure 1) actually deposits an activating agent. The second half of the two part binder is premixed with the powdered material.
} 
In applications where a high degree of customisation is not the principle driver, Rapid Manufacturing can still be cost effective. While conventional mass production remains economical for large batches of like components, Rapid Manufacturing has been shown to have the potential of reducing production run costs for low volumes of products. Analysis of manufacturing and construction based examples can be found in [22] and [23] respectively.

\section{Digital Fabrication and Rapid Manufacturing in Construction}

In the manufacturing sector, automation using industrial robots and machines that used direct numerical control took hold in the 1960s. The development of microprocessors delivered computer numerical control in the 1970s and the computer revolution in the 1980s brought computer aided design software, delivering the power of manipulating geometry to the designer. Developments in $\mathrm{CAD}$ and $\mathrm{CNC}^{5}$ also delivered a commercial Rapid Manufacturing process (Stereolithography) in 1987. In the 1990s advanced parametric modelling was introduced and the industry has enjoyed the development of the integration of design and analysis tools and machine control, in addition to the advancements in Rapid Manufacturing processes and materials.

These aerospace and automotive sector revolutions are now a growing feature of today's construction industry. The Shimitsu, Obayashi corporations incorporated robotics in the 1990s to carry out various automated operations [24]. Robotics are also finding other ways to augment the construction process, such as power floating concrete. Perhaps one of the most striking developments is the introduction Digital Fabrication, the application of large scale $\mathrm{CAD} / \mathrm{CAM}^{6}$ techniques for the creation of building structural components and façades. One of the first examples was The Vila Olimpica in Barcelona, Spain constructed between 1989-1992 [25]. It was designed by Frank Gehry (Gehry Partners, Los Angeles, US [26]) and constructed by Permasteelisa (Vittorio Veneto, Italy [27]). Designed in CATIA, a solid modelling tool designed for the aerospace industry, the model data was also used in the fabrication of the structure. This partnership has produced many other projects such as the Guggenheim Museum at Bilbao, Spain (1997).

The common applications of CNC manufacturing in construction are cutting processes used to form structural steel members and milling processes employed to create large moulds from polystyrene for casting concrete or shaping glass. Gehry's Zollhoff Towers (Dusseldorf, Germany) used CNC techniques in the manufacture of major structural components. The towers are three blocks of offices, each made up of a series of 'twisted' and 'warped' rises in which every wall panel is curved. One set of offices is finished in metal, one painted and one in brickwork. CNC Plasma-arc cutting of sheet steel was used to form the masonry supports. The load bearing, curved, external wall panels were produced using blocks of lightweight polystyrene and CNC machined to produce hundreds of different curved moulds that became the forms for casting the reinforced concrete.

The computer has also made an impact on design. The BMW pavilion for the 1999 motor show was designed by Bernhard Franken. The form of the structure was defined by a computer simulation of two water droplets merging. Data from the simulation was used to define the space frame which was cut from aluminum using $\mathrm{CNC}$ processes. The frame supported a clear skin comprising of many double curved, acrylic panels. These were formed by heating the pre cut acrylic panels and allowing

\footnotetext{
${ }^{5}$ Computer Numeric Control.

${ }^{6}$ Computer Aided Manufacturing.
} 
them to deform over polystyrene moulds that had been created using multi-axis milling. This latter process is also exemplified by the curved glass panes found in the Conde Nast Employee Cafeteria (Gehry, New York, 2000).

The use of CNC technologies to produce art/architectural pieces is exemplified by the work of Objectile [28], a design and architecture workshop based in Paris, France. Objectile combines engineering, mathematics, technology, and philosophy to work on the industrial design and manufacturing of curved and variable forms of every proportion, including sculpture, design, furniture, building components, architecture, town planning or landscaping. They have developed their own software for controlling multi-axis milling tools.

The desire to create freeform structures has been explored by Kevin Rotheroe and lead to the development of 'Freeform Tubes' [29]. The shape of the structural components can be manufactured to requirement, forming interlocking, freeform structural members. The process casts steel into moulds formed through CNC machining.

The construction industry is becoming familiar with Digital Fabrication. Leading designers Such as Buro Happold (London, UK) are using solid modelling tools to resolve freeform architectural surfaces into efficient, buildable structures. Rapid Prototyping is finding it's place in the design process: Foster and Partners (London, UK) have a suite of modelling equipment that includes CNC laser cutting tools and a 3D printing process; 3D model production bureau's such as Slovinova (Hampshire, UK [30]), specialise in producing 3D architectural models; there have been exhibitions of architecture and digital fabrication [31]; and academic publications on the topic [32]. The use of solid modelling is creating a new vehicle for design information transfer. Digital information is being used increasingly to communicate design parameters to structure and façade manufactures and to address this, Gehry Technologies have developed their 'Digital Project' software, based on CATIA.

Today Construction is using $\mathrm{CAD} / \mathrm{CAM}$ to liberate architectural possibilities and all indications are that a new era of digital design is on the horizon. Currently the shape of construction components can be controlled from a digital model. Once manufactured, these can be assembled on site and advances in technology are often seen as automation of assembly [12]. In 1997, Pegna [33] suggested that a principle problem with this wisdom was due to the complexity of the elemental tasks required for assembling a building. Pegna suggested that automation would be more effective employing larger numbers of simpler operations. Inspired by Navajo sand painting, Pegna developed a process to explore this principle. The process used a blanket sand deposition process followed by selective deposition of Portland cement through a mask, using steam as the binding agent. The process yielded reasonable material properties and highlighted potential savings by reusing unused material as part of the process. The work was promising and demonstrated that the principles of Rapid Manufacturing could be applied to construction materials.

More recently, Contour Crafting [34] has been demonstrated to produce large $(>1 \mathrm{~m})$ structures. In essence, the process produces a replacement for the structural concrete block wall commonly used in UK house construction. The process extrudes the internal and external 'skin' of the wall to form a permanent shutter that is then backfilled this with a bulk compound similar to concrete. Using thixotropic materials with rapid curing properties and low shrinkage characteristics, consecutive layers of the wall can be rapidly built up. The wall material deposition process is a two stage operation. In order to improve the finish of the visible surfaces, the shutter material is shaped by a secondary manipulator, or trowel, as it is extruded. The combination of processes results in a system that can deposit (relatively) large quantities of material 
while maintaining a high quality surface finish. This technology is currently leading the field in terms of a demonstrated new approach to automating the construction process.

\section{Future Applications for Rapid Manufacturing}

To generate new construction applications for additive manufacturing technology that are grounded by industry, 17 practitioners and 6 academics, representing 13 organisations were canvassed for ideas during the course of a one day workshop $^{7}$. Engineers, architects, construction managers, academia, CAD software houses and construction innovations developers were represented. A seminar delivered a contextual background similar to that given in the previous sections. Two groups were selected such that each group was reasonably diverse in terms of the professions represented. In each of the groups, each person was asked to provide answers to the question: If you could have a 'freeform machine' today what would you use it for?

The answers fell into broad categories that reflected the elements of a building and construction. Six technology categories also emerged. Potential applications tended to fall into those that can be delivered through improving computing technology and those that require a physical process and/or materials. Of the latter, some applications reflected what can be achieved through Rapid Manufacturing and CAD/CAM technologies today. Examples of others reflected what is being achieved in high end architecture though Digital Fabrication. More far reaching applications tended to fall into three further categories: new specialist processes that provide a solution for use in a conventional construction environment; those that would be particularly suited to off site fabrication using new technologies; and those applications that are only conceivable when new technologies are applied to the construction of the whole structure. Table 1 rationalises the answers relating to structure assembly, full details are given in [35].

Table 2:

Possibilities for processes for creating freeform structures.

The sense of those who contributed to Table 2 was that freeform approaches could help in the manufacture of complex forms and in component and systems integration. The first column in Table 2 describes the element of the building where an application may lie. The second relates to the development systems that could be used along side traditional construction methods. The third column, reaches a little further and considers integrating systems, perhaps on a panelised or volumetric basis. The final column describes possible applications when mega-scale, most probably on site, approaches are considered. Table 2 demonstrates that, conceptually at least, the latter category offers the most possibilities across all aspects of the construction process. Once the additive manufacturing, layer by layer approach is considered for construction, the possibilities for system integration and reduction of materials interfaces are striking:

- Integration of mechanical and electrical services with in the structure means reduced amounts of wasteful and time consuming builders work;

- better control over the deposition of build material will result in better internal and external finishes, completed as the structure is built;

- being able to consider the structure as a homogenous unit will negate the need for difficult interface detailing, reducing the chance for error and hence costly remedial works;

\footnotetext{
${ }^{7}$ Workshop entitled 'Freeform Construction,' held at Loughborough University on the $29^{\text {th }}$ June 2005.
} 
- the coupling of digitally controlled process with solid modelling techniques will mean greater design freedom at no extra cost.

The group did highlight obstacles for such new radical technologies. Amongst concerns were the political will, the business case and building regulation/legislation compliance.

\section{Freeform Construction: Mega-Scale Rapid Manufacturing for Construction.}

The workshop identified many potential applications for Rapid Manufacturing in construction. These applications could be broadly classified by scale; desktop, room/large component, whole building. many of the desktop applications referred to models to augment design communication and problem resolution. Consideration of applications at a volumetric or whole building scale delivered conceivable benefits. Generally in construction, as the volume of the considered portion of the building increases, so does the number of assembly and craft operations that are required to realise it. If mega-scale Rapid Manufacturing can replace these operations then the coordination and on-site operations for the creation of large sections of the building could be of worth. To achieve all the required function, however, the precise control of the material deposition is required. The control over the material deposition is referred to here as the resolution of the process. If precise control over material placement is possible, then certainly channels, voids and surface textures could be incorporated within a structural element, such as a wall. It may also be possible to control the properties if the build material itself by applying different binding agents and curing processes. Even functionally grading materials to vary properties may be achievable. This has lead the authors to define the term 'Freeform Construction' as:

'Processes for integrated building components which
demonstrate added value, functionality and capabilities
over and above traditional methods of construction.'

Unfortunately there is a conflict between the rate at which material must be deposited and the resolution required to define the design features. Figure 2 depicts an idealised representation of the resolution/deposition rate paradox.

Fig. 2. The relationship between production processes in terms of build resolution and material deposition rates.

The relationships for a number of processes are detailed. Micro Rapid Manufacturing processes are those that build very small components. The Proform Microstereolithography process produces parts to a maximum volume of $1050 \mathrm{~mm}^{3}$, but to a resolution of $10 \mu \mathrm{m}$ [36]. Existing 'desktop' scale Rapid Manufacturing processes that can produce desktop sized items, such as Selective Laser Sintering and Stereolithography. If a construction process such as slip forming is considered, volume deposition is possible, but at the expense of increasing tolerances. If Freeform Construction is to be realised, volume deposition is required whilst retaining material placement precision. Figure 2 represents this with three square blocks. Existing process resolution diminishes as the deposition rate increases, (squares $1 \rightarrow 2$ ). Freeform Construction processes will need to deliver high deposition rate and high resolution, simultaneously (squares $1 \rightarrow 3$ ). 


\section{The Viability of Freeform Construction}

Besides the human factors, there are three key issues that will have implications for the impact of Freeform Construction on traditional methods;

- cost,

- time,

- value added.

These issues were tested in a series of pilot studies that extrapolated the performance characteristics of existing processes and materials in order to evaluate the viability of a hypothetical mega-scale Rapid Manufacturing processes.

\section{Cost}

To identify the principle cost issues associated with using additive processes for building large structural components a hypothetical wall structure was devised, based on a typical domestic housing applications in the UK. The wall comprised of $13 \mathrm{~mm}$ of internal plaster finish on a $100 \mathrm{~mm}$ concrete block, with a $50 \mathrm{~mm}$ cavity and $100 \mathrm{~mm}$ external facing brick. Fixings, brick ties, insulation, etc. were neglected. The wall was assumed to be $5 \mathrm{~m}$ long by $3 \mathrm{~m}$ high.

There is one Rapid Manufacturing process that uses a material that is of a similar type to some of those found in construction. Z Corporation's 3D printing process (Figure 1) uses powdered gypsum as the build material. Their largest machine (the 810 ) can produce parts $600 \mathrm{~mm}$ by $500 \mathrm{~mm}$ by $400 \mathrm{~mm}$. It is simple to envision how a scaled up version may perform; i.e. double the number of printer heads ejecting the binder activating agent and the time it takes to raster across each layer will half, leading to a reduction in build time; double the build area and the build time could double.

The data used to derive the 3D Printing calculations were based on a hypothetical Z Corporation machine those performance was estimated using commercially available machine data. The published vertical height build speed of $43 \mathrm{~mm} / \mathrm{hr}$ was maintained. The printed wall was assumed to produce a finished wall with no additional post processing requirement. The material was assumed to be fit for purpose. The machine costs were based on a linear scaling of the current relationship between product build volume and cost. The material volumes of the 3D printed 'brick' and 'block' leaves are assumed to be $50 \%$ of the overall volume. The traditional construction costs and times were estimated using Spon's guide (Anon. 2002a, Anon. 2002b). Details are given in [37].

In Figure 3, the plain wall construction cost is shown on the right and serviced wall cost on the left. The serviced wall includes the installation of multiple electrical conduits such as may be found in commercial kitchens. This was introduced to consider the implications of building in function (adding value). The production of the wall using current 3D printing materials is prohibitively expensive. The Z Corporation's build material is currently aimed at the hand held/desktop modelling market. Figure 3 shows that the material cost would have to be close to that of raw gypsum to be economically viable. The figure does demonstrate, however, that the case for highly serviced walls (a degree of systems integration, or increased functionality) does improve the cost argument for the Freeform Construction Process.

Fig. 3. Wall construction cost comparison. 


\section{Time}

Using the same example, the wall was evaluated in terms of build time to completion. Figure 4 compares building using traditional process and the constant build rate of $43 \mathrm{~mm} / \mathrm{hr}$ associated with the 810 machine. The steps in the traditional methods come from having to leave every $\sim 1 \mathrm{~m}$ height in brickwork overnight for the mortar to cure (maximum weight on wet mortar). Excepting that it was assumed that there was no operational efficiency in the labour allocation (continuous work) and neglecting the set up time for the machine, the $3 \mathrm{D}$ printing is comparable in build time to traditional methods.

Fig. 4. Comparison of time to completion.

\section{Value added}

Adding more functionality to a product at no extra manufacturing cost increases process viability. The thermal conductivity of primary building materials is important and the requirements for greater levels of insulation are only going to increase. Using a primary build material with a low thermal conductivity is therefore beneficial and insulating concrete blocks are a common solution for the UK climate. The investigation considered a number of potential wall panel designs. Using the $\mathrm{Z}$ Corporation 3D printing process, the panels were constructed from gypsum. The internal geometry of the panels were designed to test the extent to which the material geometry could be used to improve function. Two of the panels are depicted in Figure 5. Each panel, including a panel of solid material, was tested on a UKAS accredited EN 12667 guarded hot plate apparatus. Although this does not generate the industry accepted $k$-value (thermal conductivity, $\mathrm{W} / \mathrm{mK}$ ), the results give a good indication of performance.

Fig. 5. Two panel designs for minimising thermal conductivity.

Figure 6 shows approximate regions of $k$-values for typical building materials, plotted against material density ${ }^{8}$. The test panels demonstrate a performance at least as good as aerated concrete. The performance is achieved through maximising the resistance of the conduction path. The panel in the left of Figure 5 had a $k$-value of $0.112 \mathrm{~W} / \mathrm{mK}$, nearly half that of the right hand panel. These designs were exploratory and there is some room to improve the thermal resistance characteristics.

Fig. 6. Thermal conductivity/density characteristics for building materials and test panels.

\section{Conclusions}

Parametric solid modelling tools are becoming more common in the construction arena and Rapid Manufacturing is beginning to have an impact in the design process. Digital Fabrication is enabling the production of buildings with freeform surfaces, but it is not new process technology. The clients of the construction industry are asking leading designers to build structures that cannot be built by any known method today; new processes are a likely solution. There are many well understood problems facing construction that can be tackled by new processes [38]. The latest European call has stated the requirement for new process and new materials for

\footnotetext{
${ }^{8}$ It should be noted that the test panels are not homogenous and so the average bulk density was used.
} 
construction [6]. New processes will drive down the cost of existing methods and will filter down to the domestic sector, much as the Tunnelform system did, moving from Civil Engineering to the construction of dwellings [39].

Freeform Construction is one possible response to these calls. The industry has the skills to fully engage with the concept. The pilot studies have identified that:

- Materials cost will be an important issue;

- these process are probably not going to be faster than traditional approaches;

- greater performance can be achieved through clever use of geometry.

The processes capable of delivering components large enough for a building structures is unlikely to be a scaled up version of a current process used for Rapid Manufacturing. Specialist applications will need to be developed for specific tasks. Material properties and process characteristics will be integral to the development of these new delivery processes.

\section{Acknowledgements}

The Authors would like to thank the EPSRC for the funding of this project through the IMCRC at Loughborough University. We would like to thank BPB plc and $\mathrm{Z}$ Corporation for their support and in particular the contributions of Keith Humphrey and Tom Clay.

\section{References}

[1] T. Wohlers, Rapid Prototyping, Tooling \& Manufacturing: State of the industry, Wohlers Associates, Colorado, USA, 2004.

[2] T. Kvan and B. Kolarevic, Rapid Prototyping and its application in architectural design, Automation in Construction, Vol. 11, No. 3, April 2002, pp. 277-278.

[3] J.J. Broek, I. Horváth, B. Smit, A.F. Lennings, Z. Rusák and J.S.M. Vergeest, Free-form thick layer object manufacturing technology for large-sized physical models, Automation in Construction, Vol. 11, No. 3, April 2002, pp. 335-347.

[4] M. Burry, Rapid Prototyping, CAD/CAM and human factors, Automation in Construction, Vol. 11, No. 3, April 2002, pp. 313-333.

[5] A. Simondetti, Computer-generated physical modelling in the early stages of the design process, Automation in Construction, Vol. 11, No. 3, April 2002, pp. 303311 .

[6] Strategic Research Agenda for the European Construction Sector: Achieving a sustainable and competitive construction sector by 2030, European Construction Technology Platform., 23rd December, 2005, Available: www.ectp.org.

[7] P. Guthrie, S. Coventry, C. Woolveridge, S. Hillier and R. Collins, The reclaimed and recycled construction materials handbook, London, CIRIA, 1999.

[8] M. Latham, Constructing the Team, HMSO, London, 1994. 
[9] J. Egan, Rethinking construction, Department of the Environment, London, 1998.

[10] H. Lovell, Modern methods of house building, Parliamentary Office of Science and Technology, London, 2003.

[11] A. Gibb and M. Pendlebury, Standardisation and pre-assembly project tool kit, CIRIA, London, 2003.

[12] E. Gambao, C. Balaguer and F. Gebhart, Robot assembly system for computerintegrated construction, Automation in Construction, Vol. 9, No. 5, September 2000, pp. 479-487.

[13] H.B. Kuntze, U. Hirsch, A. Jacubasch, F. Eberle and B. Goller, On the dynamic control of a hydraulic large range robot for construction applications, Automation in Construction, Vol. 4, No. 1, March 1995, pp. 61-73.

[14] S.J. Lorenc, B.E. Handlon and L.E. Bernold, Development of a robotic bridge maintenance system, Automation in Construction, Vol. 9, No. 3, May 2000, pp. 251-258.

[15] L. Werner, Experiences with the construction of a building assembly robot, Automation in Construction, Vol. 4, No. 3, March 1, 1995, pp. 45-60.

[16] R.L. Williams, J.S. Albus and R.V. Bostelman, Self-contained automated construction deposition system, Automation in Construction, Vol. 13, No. 3, May 2004, pp. 393-407.

[17] Y. Yamazaki and J. Maeda, The SMART system: an integrated application of automation and information technology in production process, Computers in Industry, Vol. 35, No. 1, February 1998, pp. 87-99.

[18] Manufacturingtalk, SMD builds fully dense, near-net-shape structures, Published: 13/07/2004, Accessed: May 2006, Available:

www.manufacturingtalk.com/news/rll/r1l100.html

[19] Optomec, LENS applications, Assessed May 2006, Available: www.optomec.com

[20] K. Arcaute, L. Ochoa, B. Mann and R. Wicker, Hydrogels in Stereolithography, in proceedings of Solid Freeform Fabrication symposium, Austin, Texas, US, 2005, pp. 434-445.

[21] Invisalign, Invisalign home page, Accessed May 2006, Available: www.invisalign.com

[22] N. Hopkinson and P. Dickens, Analysis of rapid manufacturing - Using layer manufacturing processes for production, in proceedings of the Institution of Mechanical Engineers, Part C: Journal of Mechanical Engineering Science, Special issue on Rapid Manufacturing, Vol. 217, No 1, 2003, pp. 31-40.

[23] R.A. Buswell, R.C. Soar, M. Pendlebury, A. Gibb, F. Edum-Fotwe and A. Thorpe, Investigation of the potential for applying freeform processes to construction, in 3rd International Conference on Innovation in Architecture, 
Engineering and Construction (AEC), Rotterdam, Netherlands, June 2005, pp. 141-150.

[24] S. Howe, Designing for automated construction, Automation in Construction, Vol. 9, No. 3, May 2000, pp. 259-276.

[25] D. Schodek, M. Bechthold, K. Griggs, k. Kao and M. Steinberg, Digital design and manufacturing: CAD/CAM applications in architecture and design, 1st ed, Hoboken, New Jersey: Wiley and Sons, 2005.

[26] Gehry Technologies, Gehry Technologies, Accessed May 2006, Available: www.gehrytechnologies.com

[27] Permasteelisa Group, Permasteelisa Group, Accessed May 2006, Available: www.permasteelisa.com

[28] FRAC Centre, Archilab 1999, Accessed May 2006, Available: www.archilab.org/public/1999/artistes/obje01en.htm

[29] K.C. Rotheroe, Architecture Week, Published 27/10/2000, Accessed May 2000, Available: www.architectureweek.com

[30] Solinova, Solinova Realising innovation, Accessed May 2006, Available: www.solinova.co.uk

[31] M. Stacey, P. Beesley and V. Hui, Digital fabricators, 1st ed, Waterloo, Canada: University of Waterloo School of Architecture Press, 2004, pp. 95.

[32] Y.E. Kalay and M.J. Skibniewski (ED), Special issue: Rapid Prototyping, Automation in Construction, Vol. 11, 2002.

[33] J. Pegna, Exploratory investigation of solid freeform construction, Automation in Construction, Vol. 5, No. 5, February 1997, pp. 427-437.

[34] B. Khoshnevis, Automated construction by Contour Crafting - Related robotics and information sciences, Automation in Construction Special Issue: The Best of ISARC 2002, Vol. 13, No. 1, 2004, pp. 5-19.

[35] R.A. Buswell, R.C. Soar, A. Gibb and A. Thorpe, Freeform construction application research, in Proceedings of Advances in Engineering Structures, Mechanics and Construction, Waterloo, Canada, May 2006.

[36] Proform, Microstereolithography, Accessed 2006, Available: www.proform.ch

[37] R. Buswell A., R. Soar, A. Gibb and A. Thorpe, The potential of Freeform Construction processes," in proceedings of Solid Freeform Fabrication symposium, Austin, Texas, US, 2005, pp. 505-512.

[38] J. Egan, Rethinking Construction, Department of the Environment, London, 1998.

[39] The Concrete Centre, High performance buildings: Using Tunnel Form Concrete Construction, The Concrete Centre, Camberly, Surrey, UK, 2004. 


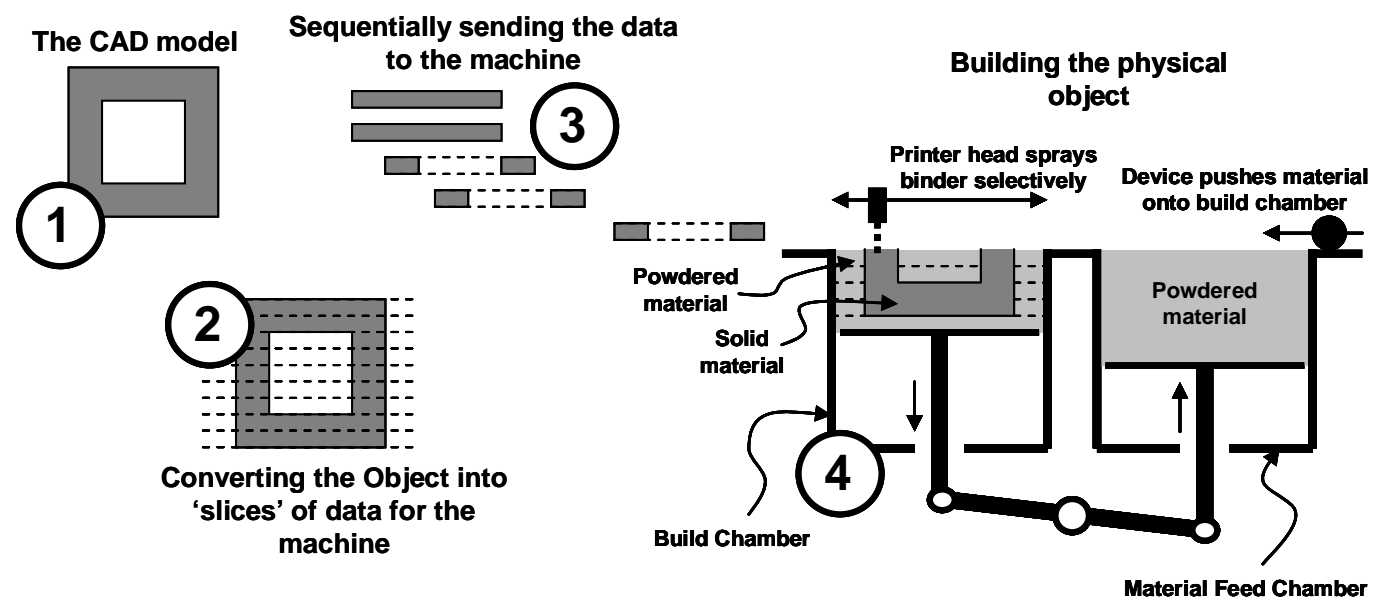

Fig. 1. A representation of the 3D printing process. 


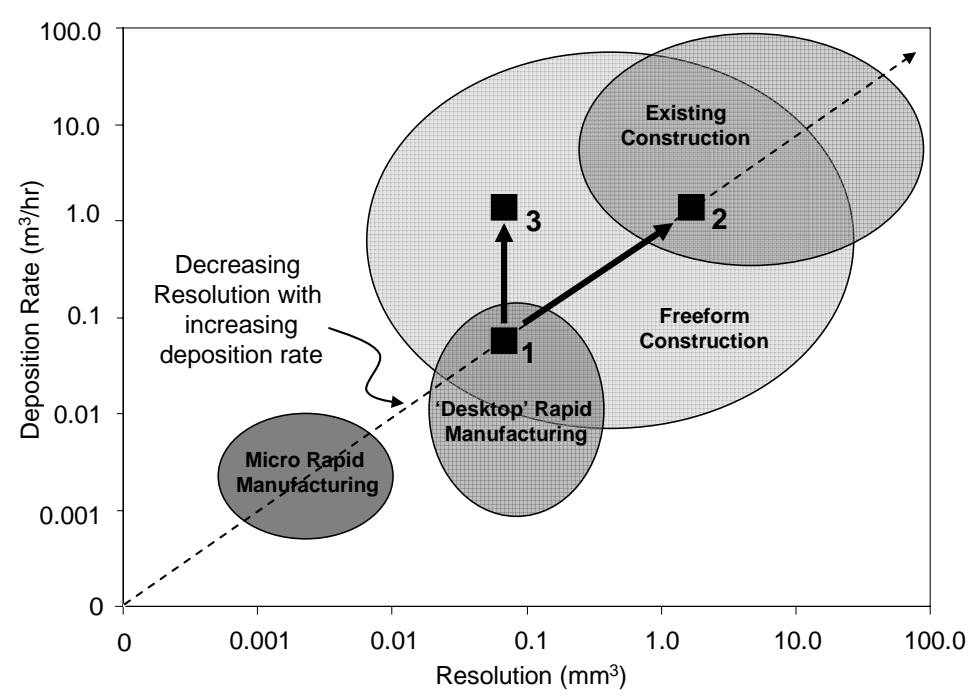

Fig. 2. The relationship between production processes in terms of build resolution and material deposition rates. 


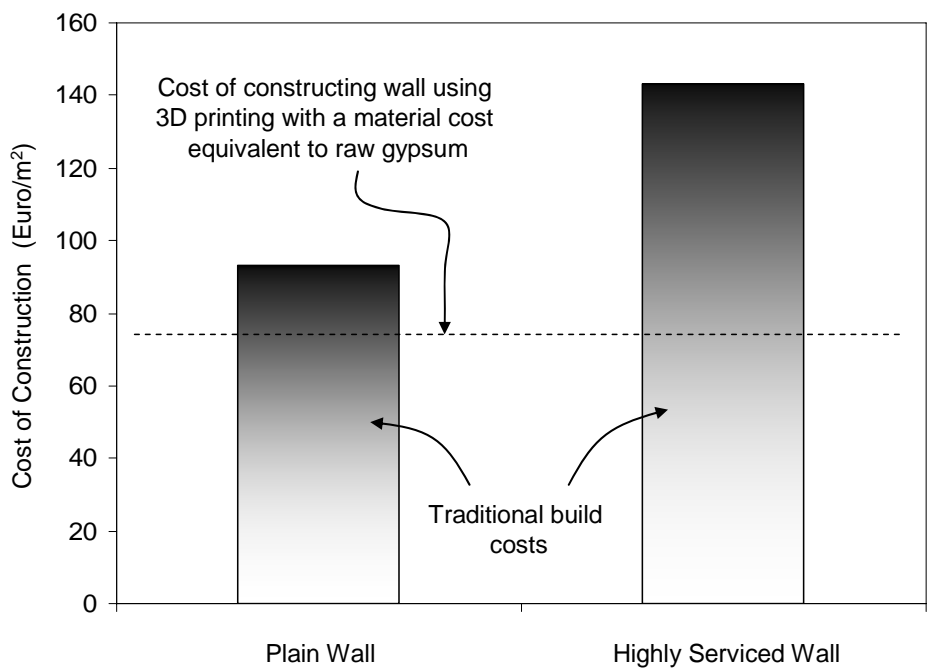

Fig. 3. Wall construction cost comparison. 


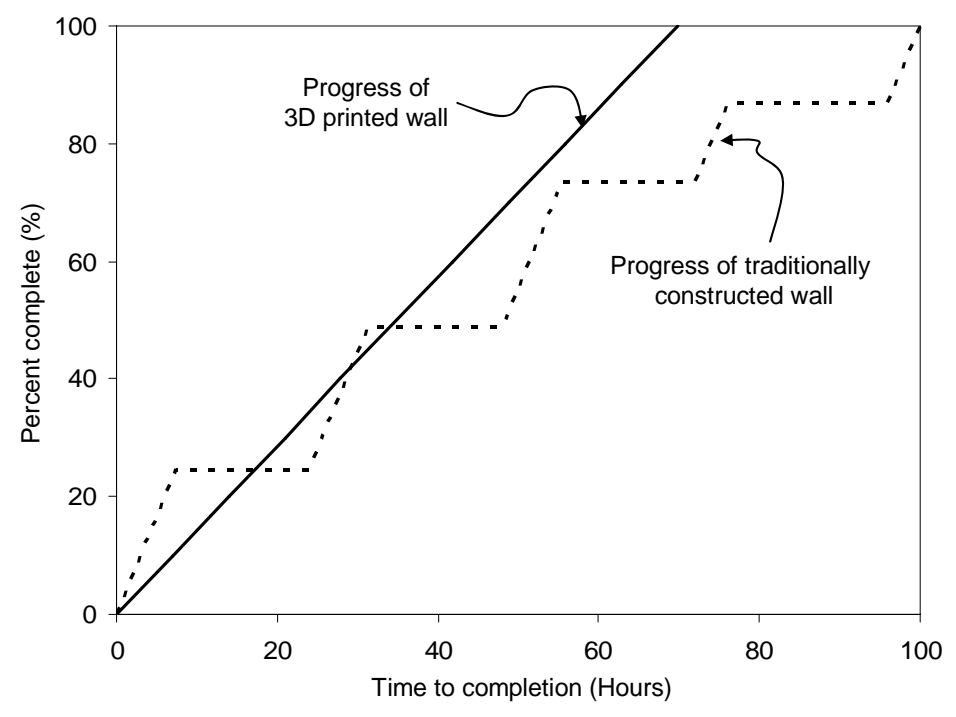

Fig. 4. Comparison of time to completion. 


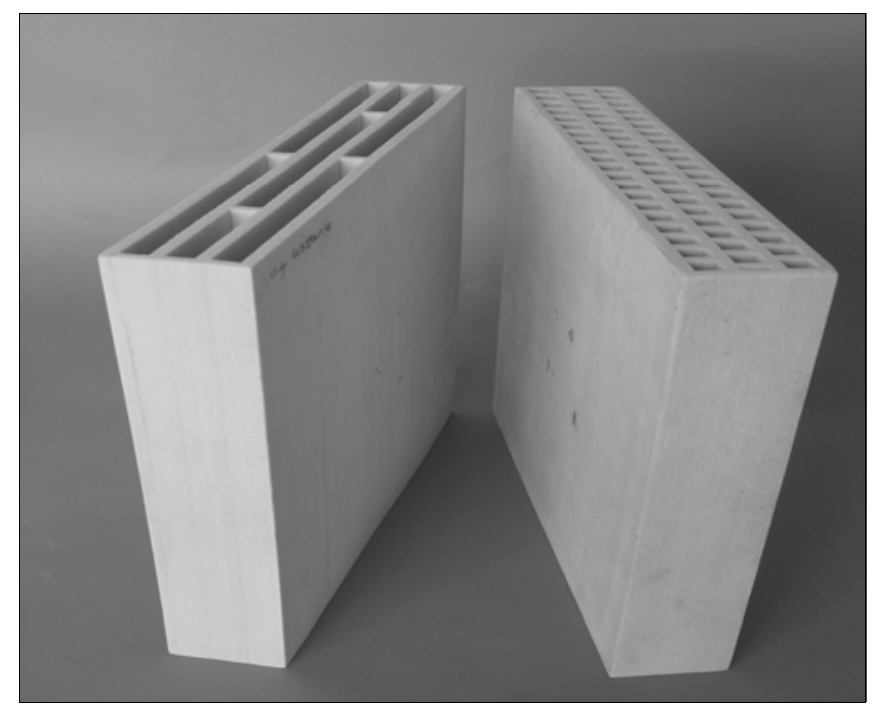

Fig. 5. Two panel designs for minimising thermal conductivity. 


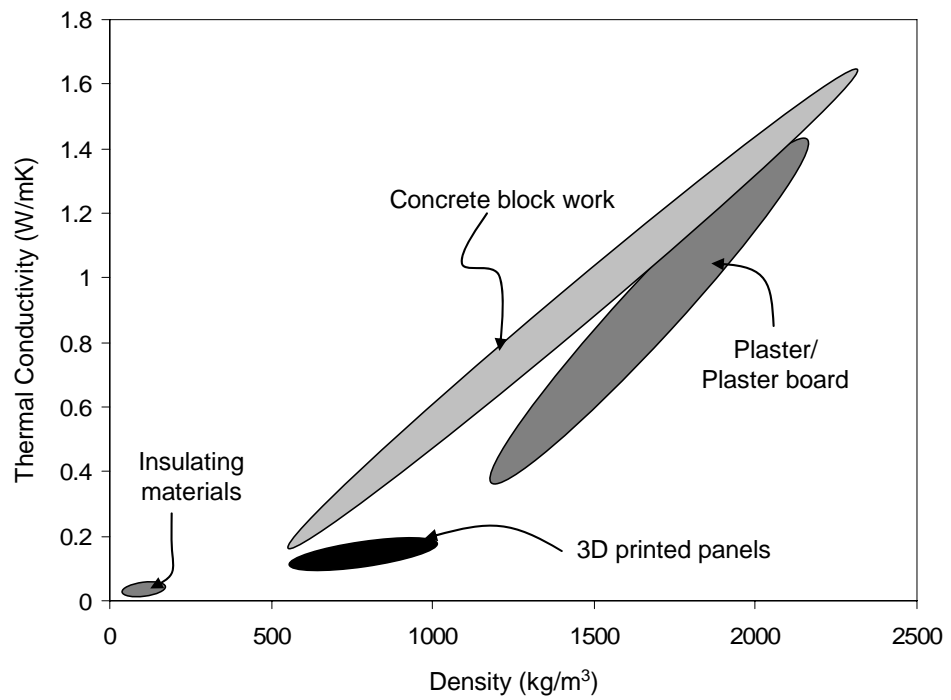

Fig. 6. Thermal conductivity/density characteristics for building materials and test panels. 
Table 1:

Summary of common Rapid Manufacturing techniques.

\section{Process Description}

Liquid photopolymer resin is held in a tank. A flat bed is immersed

Stereolithography to a depth equivalent to one layer. Lasers are used to activate the resin and cause it to solidify. The bed is lowered and the next layer is built and so on.

Fused Deposition Extrudes a narrow bead of hot plastic and is selectively deposited Modelling where it fuses to the existing structure and hardens as it cools

Selective Laser

Sintering

Utilises a laser to partially melt successive layers of powder. One layer of powder is deposited over the bed area and the laser just targets the areas that are required to be solid in the final component.

Based on inkjet printer technology. The inkjet selectively deposits a

3D Printing liquid binder onto a bed of powder. The binder effectively 'glues' the powder together 
Table 2:

Possibilities for processes for creating freeform structures.

\begin{tabular}{|c|c|c|c|}
\hline Building Element & $\begin{array}{l}\text { Mix of Traditional } \\
\text { \& Hybrid } \\
\text { Technologies }\end{array}$ & $\begin{array}{l}\text { Technologies For } \\
\text { Off Site } \\
\text { Applications }\end{array}$ & $\begin{array}{l}\text { Large Scale Whole } \\
\text { Structure, On Site } \\
\text { Approaches }\end{array}$ \\
\hline $\begin{array}{l}\text { Design }+ \\
\text { Communication }\end{array}$ & & & $\begin{array}{l}\text { Generate new } \\
\text { architectural } \\
\text { possibilities in addition } \\
\text { to improving } \\
\text { personalised/ergonomic } \\
\text { design - no more } \\
\text { straight lines and } \\
\text { corners. }\end{array}$ \\
\hline Structure & & & $\begin{array}{l}\text { Possibility of } \\
\text { tension/compression } \\
\text { structures. }\end{array}$ \\
\hline Roofs \& Canopies & & & $\begin{array}{l}\text { Possibility of } \\
\text { monolithic curved } \\
\text { enclosures. }\end{array}$ \\
\hline $\begin{array}{l}\text { Floors, Ceilings and } \\
\text { Walls }\end{array}$ & & $\begin{array}{l}\text { Integrating service } \\
\text { systems into } \\
\text { partitions and } \\
\text { volumetric } \\
\text { assemblies. }\end{array}$ & $\begin{array}{l}\text { Integrating service } \\
\text { systems into building } \\
\text { fabric. }\end{array}$ \\
\hline $\begin{array}{l}\text { Surfaces, Finishes } \\
\text { \& Decoration }\end{array}$ & $\begin{array}{l}\text { Embedding control } \\
\text { systems in surfaces. }\end{array}$ & $\begin{array}{l}\text { Possibility of } \\
\text { seamless finishes. }\end{array}$ & $\begin{array}{l}\text { Possibility of joint-less } \\
\text { construction, precise } \\
\text { surface property } \\
\text { control. And greater } \\
\text { variety of surface } \\
\text { finishes. }\end{array}$ \\
\hline Openings & & $\begin{array}{l}\text { Possibility of } \\
\text { structural glazing } \\
\text { systems. }\end{array}$ & $\begin{array}{l}\text { Possibility of structural } \\
\text { glazing systems. }\end{array}$ \\
\hline $\begin{array}{l}\text { Fixings, Flashings } \\
\text { and Junctions }\end{array}$ & $\begin{array}{l}\text { Improved weather } \\
\text { protection at service } \\
\text { penetrations. }\end{array}$ & & $\begin{array}{l}\text { Elimination of } \\
\text { troublesome system } \\
\text { interfaces. }\end{array}$ \\
\hline
\end{tabular}

